\title{
Synthesis, structure and magnetic behaviour of mixed metal leucophosphite
}

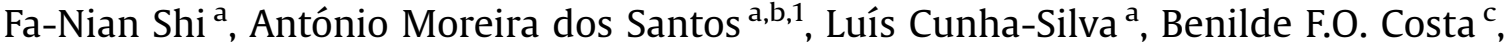 \\ Jacek Klinowski ${ }^{\mathrm{d}}$, Filipe A. Almeida Paz ${ }^{\mathrm{a}}$, Vítor S. Amaral ${ }^{\mathrm{b}}$, João Rocha ${ }^{\mathrm{a}}$, Tito Trindade ${ }^{\mathrm{a}, *}$ \\ a Department of Chemistry, CICECO, University of Aveiro, 3810-193 Aveiro, Portugal \\ b Department of Physics, CICECO, University of Aveiro, 3810-193 Aveiro, Portugal \\ c CEMDRX, Department of Physics, University of Coimbra, 3004-516 Coimbra, Portugal \\ d Department of Chemistry, University of Cambridge, Lensfield Road, Cambridge CB2 1EW, UK
}

\section{A R T I C L E I N F O}

\section{Article history:}

Received 6 December 2007

Received in revised form

13 February 2008

Accepted 20 February 2008

Available online 4 March 2008

Keywords:

Hydrothermal synthesis

Leucophosphite

Ferric phosphate

Vanadium

Magnetism

\begin{abstract}
A B S T R A C T
A synthetic analogue of leucophosphite, an iron phosphate, was synthesized hydrothermally at $180{ }^{\circ} \mathrm{C}$ and its chemical composition determined to be $\left\{\mathrm{K}\left[(\mathrm{FeV})\left(\mathrm{PO}_{4}\right)_{2}(\mathrm{OH})\left(\mathrm{H}_{2} \mathrm{O}\right)\right] \cdot \mathrm{H}_{2} \mathrm{O}\right\}$. The compound crystallizes in the monoclinic $P 2_{1} / c$ space group, with $a=9.7210(19) \AA, b=9.6500(19) \AA, c=12.198(4) \AA$ and $\beta=128.569(18)^{\circ}$. While the original all-iron compound is reported to be antiferromagnetic, the inclusion of substitutional vanadium(III) ions renders the structure ferrimagnetic. Diffraction studies and magnetic characterization show that iron and vanadium are disordered throughout the crystallographic sites. The magnetic behaviour of this system was interpreted in terms of a classic ferrimagnetic mean field model, consisting of two antiferromagnetically coupled non-crystallographic "sublattices".
\end{abstract}

(c) 2008 Elsevier Inc. All rights reserved.

\section{Introduction}

The ability to control the spin state at the atomic or molecular level can provide important technological breakthroughs in areas such as data storage, quantum computing or advanced magnetoelectric sensors [1]. Although the occurrence of spontaneous magnetization is highly desirable for technological applications, the dominant magnetic interaction in most systems is antiferromagnetic. Two common strategies to tune the magnetization at the nanolevel are the synthesis of monodisperse magnetic nanoparticles [2] and molecular magnets [3]. In magnetic nanoparticles it is possible to take advantage of the uncompensated surface spins, which can be a considerable contribution if the particle is small enough, or induce the ferrimagnetism either by mixing two metals with different spins or by tuning the oxidation state of the magnetic centre (e.g. defect-induced ferromagnetism in $\mathrm{LaMnO}_{3+\delta}$ [4]). The same principle can be applied in antiferromagnetic clusters: a spontaneous magnetization can be induced by mixing different metals with different spins within the clusters.

\footnotetext{
* Corresponding author. Fax: + 351234370084

E-mail address: tito@ua.pt (T. Trindade).

${ }^{1}$ Current address: SNS, Oak Ridge N.L., P.O. Box 2008 MS6475, Oak Ridge, TN 37831-6475, USA.
}

Most of the research on low-dimensional magnetic systems, particularly zero-dimensional clusters, has been based on coordination polymers and hybrid organic-inorganic complexes [5], because of their synthetic tunability and also because they preserve their low-dimensional character even at low temperatures. However, such systems usually show poor heat and chemical resistance, preventing their integration in more complex systems. On the other hand, inorganic systems, oxides in particular, show enhanced thermal and chemical stability when compared to their organic counterparts, while usually having a much stronger magnetic exchange.

Metal phosphates are a rich class of inorganic compounds which usually consist of corner- or edge-sharing octahedra $\left(\mathrm{MO}_{6}\right.$, $M=$ transition metal) sharing corners with tetrahedral $\mathrm{PO}_{4}$ units. These octahedral units can form different types of metal clusters: dimers [6], trimers [7], tetramers [8], etc. From the magnetic point of view, iron phosphates have been studied in some detail $[9,10]$. In almost all instances these compounds show antiferromagnetic interactions with a high degree of frustration arising from complex topologies and competing magnetic exchange terms.

Leucophosphite is an iron phosphate mineral, first found in 1932 [11], and the structure described by Moore [12] and later further elucidated by the Rietveld refinement of powder neutron diffraction [13]. It is isostructural with tinsleyite, its aluminium analogue, and spheniscidite [14], an ammonium-containing iron aluminium phosphate. The most notable structural feature of leucophosphite is its "butterfly cluster:" a $\mathrm{Fe}_{4} \mathrm{O}_{20}$ tetramer 


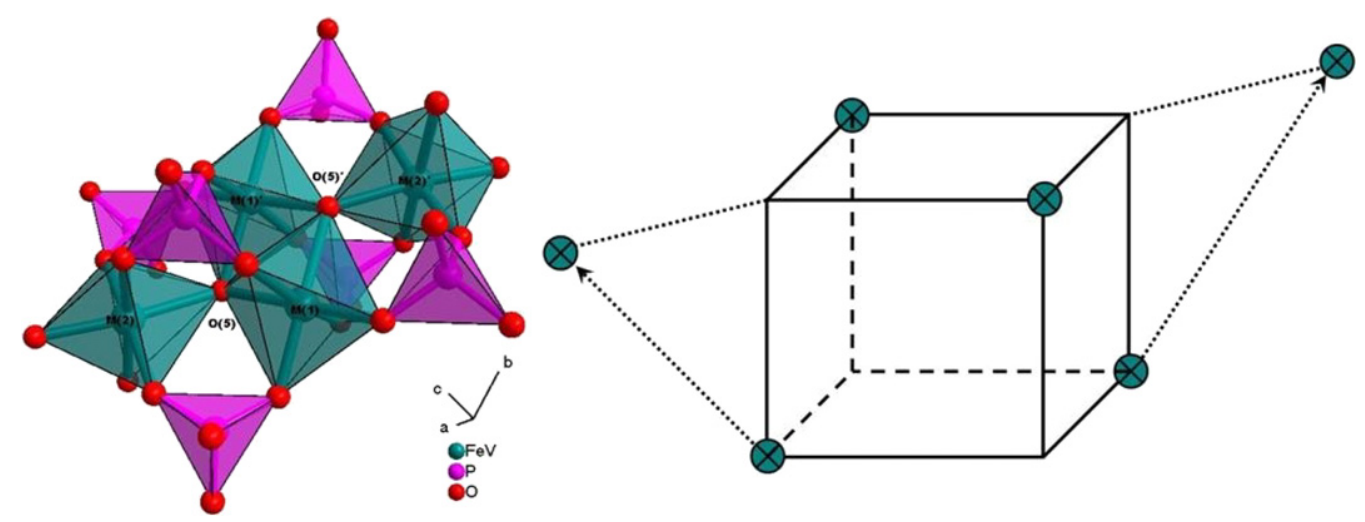

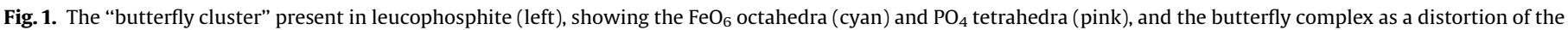
cubane arrangement (right).

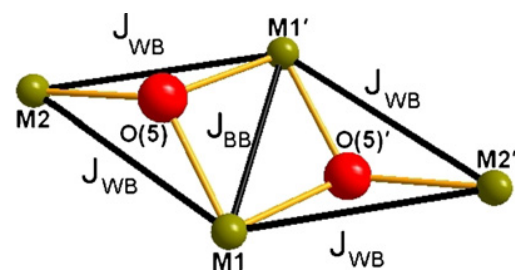

Fig. 2. Representation of the butterfly cluster from a magnetic point of view, highlighting the $M-O$ connectivity and the dominant intra-cluster exchange parameters: $J_{\mathrm{BB}}$-body-exchange, $J_{\mathrm{WB}}$ - wing-body exchange.

consisting of two edge-sharing octahedra (body) with two adjoining octahedra connected to the shared edge (wings) as shown in Fig. 1 (left). This tetramer complex can be seen as a distortion of the more common cubane tetramer (see Fig. 1 (right)).

This "butterfly cluster" unit is also observed in other metal phosphates and even in some metal-organic compounds [15]. The magnetic behaviour of this butterfly unit has been investigated in detail both in the phosphate form [10] and in the metal-organic clusters [16]. A representation of the magnetic topology of the butterfly cluster is shown in Fig. 2. Note that further inter-cluster interactions may be present through $\mathrm{PO}_{4}$ tetrahedra, but these are invariably smaller and only significant at low temperatures.

Following our recent study of metal phosphates [17], ferrimagnetism was induced here in a synthetic mixed metal phosphate $\left(\mathrm{V}^{3+}\right.$ and $\left.\mathrm{Fe}^{3+}\right)$, analogous to leucophosphite. Its magnetic properties were measured and accounted for from structural and chemical data.

\section{Experimental}

\subsection{Techniques}

FT-IR spectra were collected from $\mathrm{KBr}$ pellets (Aldrich $99 \%+$, FT-IR grade) on a Mattson 7000 FT-IR spectrometer. Thermogravimetric analyses (TGA) were carried out using a Shimadzu TGA 50, with a heating rate of $5{ }^{\circ} \mathrm{C} / \mathrm{min}$ in air, from room temperature to $1000^{\circ} \mathrm{C}$.

Scanning electron microscopy (SEM) and energy-dispersive analysis of X-rays spectroscopy (EDS) were performed using a Hitachi S-4100 field emission gun instrument at $25 \mathrm{kV}$.

Measurements of the magnetic susceptibilities of the powdered sample were performed at various temperatures, from 4.5 to $300 \mathrm{~K}$, using a Quantum Design Superconducting Quantum Interference Device (SQUID) magnetometer MPMS at the University of Porto (Portugal).

\subsection{Synthesis of $\mathrm{K}\left[(\mathrm{FeV})\left(\mathrm{PO}_{4}\right)_{2}(\mathrm{OH})\left(\mathrm{H}_{2} \mathrm{O}\right)\right] \cdot \mathrm{H}_{2} \mathrm{O}$}

All chemicals were readily available from commercial sources and used as received without further purification. Syntheses were carried out in PTFE-lined stainless steel reaction vessels $\left(40 \mathrm{~cm}^{3}\right)$, under autogenous pressure and static conditions.

The title compound was synthesized from a mixture containing $0.68 \mathrm{~g}$ vanadyl sulphate hydrate $\left(\mathrm{VOSO}_{4} \cdot \mathrm{nH}_{2} \mathrm{O}\right.$, Fluka), $0.60 \mathrm{~g}$ orthophosphoric acid (min. 85\% $\mathrm{H}_{3} \mathrm{PO}_{4}$, Merck), $1.13 \mathrm{~g}$ potassium ferric oxalate $\left(\mathrm{K}_{3}\left[\mathrm{Fe}\left(\mathrm{C}_{2} \mathrm{O}_{4}\right)_{3}\right], 99 \%\right.$, Ventron) and $0.36 \mathrm{~g}$ piperazine anhydrous $\left(\mathrm{C}_{4} \mathrm{H}_{10} \mathrm{~N}_{2}\right.$, $\geqslant 98 \%$, Merck-Schuchardt $)$ in ca. $15 \mathrm{~g}$ distilled water. This mixture was transferred to the reaction vessel and then placed inside an oven at $180^{\circ} \mathrm{C}$. The reaction proceeded for 3 days before the reaction vessel was allowed to cool in air to ambient temperature. The contents of the reaction vessel consisted of a large quantity of dark-brown prismatic crystals, whose composition was determined by single-crystal X-ray diffraction to be $\mathrm{H}_{5} \mathrm{FeVKO}_{11} \mathrm{P}_{2}$, and a small quantity of an unidentified powder impurity. The two phases were readily separated using ultra-sound (for $15 \mathrm{~min}$ ), followed by filtration and washing with copious amounts of distilled water. The title compound proved to be air- and light-stable, and insoluble in water and in organic solvents.

TGA data showing weight losses can be divided into the following steps: $103-494^{\circ} \mathrm{C},-10.44 \%$; $592-744{ }^{\circ} \mathrm{C},+1.21 \%$, while from above 744 to $1000{ }^{\circ} \mathrm{C}$ there is no further weight loss. Selected IR (in $\mathrm{cm}^{-1}$ ) data: 3444vs; 3316vs; 2365w; 1668m; $1157 \mathrm{~m}(\mathrm{sh})$; 1074vs; 985vs; 879m(sh); 644m; 620m; 583m; 544m; 427s.

\subsection{Single-crystal $X$-ray diffraction}

A suitable single-crystal of $\mathrm{K}\left[(\mathrm{FeV})\left(\mathrm{PO}_{4}\right)_{2}(\mathrm{OH})\left(\mathrm{H}_{2} \mathrm{O}\right)\right] \cdot \mathrm{H}_{2} \mathrm{O}$ was mounted on a glass fibre using Araldite Rapide [18], and positioned $60 \mathrm{~mm}$ from a KM4CCD/sapphire charge-coupled device (CCD) area detector. X-ray diffraction data were collected in the $\omega$ scanning mode at $293(2) \mathrm{K}$ on a KUMA4CCD diffractometer equipped with a MoK $\alpha$ graphite-monochromated radiation source $(\lambda=0.7107 \AA)$ and controlled by the CrysAlis CCD software package [19]. Data were corrected for the Lorentzian and polarization effects, and were reduced using the CrysAlis RED software routines [20]. The structure was solved using the Patterson synthesis algorithm implemented in SHELXS-97 [21], which allowed the immediate location of all heavy atoms, particularly $\mathrm{Fe}, \mathrm{V}$ and $\mathrm{K}$. The remaining non-hydrogen atoms were located from difference Fourier maps calculated from successive full-matrix least-squares refinement cycles on $F^{2}$ using SHELXL-97 [22]. All non-hydrogen atoms were successfully refined using anisotropic displacement parameters. 
The initial assumption of two crystallographically independent sites, each attributed to only one of the two transition metal centres (whose presence was previously unequivocally identified from EDS measurements), resulted in a rather poor structural refinement overall. It was then assumed that each crystallographic site was partially occupied instead simultaneously by vanadium and iron, and the least-squares refinement proceeded by constraining each pair of metallic centres to occupy the same crystallographic position and to share the same anisotropic displacement parameters. Unrestrained refinement for the site occupancies converged for an approximate ratio of 1:1 for the two crystallographic sites. The occupancy was ultimately fixed at 50\% for each metallic centre before the last full-matrix least-squares refinement cycles.

Hydrogen atoms associated with the coordinated $[\mathrm{O}(1 \mathrm{~W})]$ and uncoordinated $[\mathrm{O}(2 \mathrm{~W})]$ water molecules were markedly visible from difference Fourier maps calculated from successive leastsquares refinement cycles. The atomic positions for these atoms were ultimately included in the final structural model with the $\mathrm{O}-\mathrm{H}$ and $\mathrm{H} \cdots \mathrm{H}$ distances restrained to $0.84(1)$ and $1.37(1) \AA$, respectively, to ensure a chemically reasonable geometry for these molecules. The hydrogen atom belonging to the $\mu_{3}$-bridging hydroxyl group was also directly located from Fourier difference maps, and was refined with the $\mathrm{O}-\mathrm{H}$ distance restrained to 0.95(1) $\AA$ in subsequent least-squares refinements. All hydrogen atoms were refined using a riding model with an isotropic displacement parameter fixed at 1.5 times $U_{\mathrm{eq}}$ of the oxygen atom to which they are attached.

The last difference Fourier map synthesis showed the highest peak $\left(0.736 \mathrm{e}^{-3}\right)$ located $0.18 \AA$ from $\mathrm{V}(1)$, and the deepest hole $\left(-0.683\right.$ e $\left.\AA^{-3}\right) 0.74 \AA$ from $\mathrm{P}(1)$.

Crystallographic information (excluding structure factors) can be obtained free of charge from Fachinformationszentrum Karlsruhe, 76344, Eggenstein-Leopoldshafen, Germany (e-mail: crysdata@fiz-karlsruhe.de), on quoting the depository number CSD 418219.

\section{Results and discussion}

\subsection{General description}

The title compound was prepared by hydrothermal reaction at $180^{\circ} \mathrm{C}$ in the presence of piperazine, which acted as a pH mediator $(\mathrm{pH}>2)$ [11]. The same reaction, without adding piperazine to the starting material, was carried out under the same conditions $\left(180^{\circ} \mathrm{C}\right.$ for 3 days) and the final product was an unidentified phase of a black powder (powder XRD analysis), showing that piperazine is a necessary reactant to obtain the title compound. The SEM image (Fig. 3) clearly shows the octahedral habit of an individual single crystal. Chemical analysis through EDS yields the metal ratio $K: V: F e: P=1.0: 1.1: 1.0: 1.7$, very similar to the expected (K:V:Fe:P=1:1:1:2) expressed in the formula of $\mathrm{K}\left[(\mathrm{FeV})\left(\mathrm{PO}_{4}\right)_{2}(\mathrm{OH})\left(\mathrm{H}_{2} \mathrm{O}\right)\right] \cdot \mathrm{H}_{2} \mathrm{O}$. The experimental powder XRD spectrum of the compound and that simulated from the singlecrystal structural data are in good agreement, although a very small impurity peak at $20^{\circ}(2 \theta)$ is present (noted as * in Fig. 4 ). The TG data (see the experimental section) show weight changes happening in two stages. The first stage, from 103 to $494^{\circ} \mathrm{C}$ with a weight loss of $-10.44 \%$, is consistent with the release of $\mathrm{H}_{2} \mathrm{O}$ and $\mathrm{OH}$ groups (calculated value: $-11.57 \%$ ). The second stage, between 592 and $744{ }^{\circ} \mathrm{C}$ with a weight increment of $+1.21 \%$, can be understood as the oxidation of $\mathrm{V}^{3+}$ into $\mathrm{VO}^{2+}$ (calculated value: $+2.06 \%$ ) in air. The FT-IR spectrum shows the typical bands of the $\mathrm{OH}$ group and $\mathrm{H}_{2} \mathrm{O}$ at 3444,3316 and $1668 \mathrm{~cm}^{-1}$ on one side, and stretching bands of $\mathrm{PO}_{4}^{3-}$ at 1157,1074 and $985 \mathrm{~cm}^{-1}$ on the other.

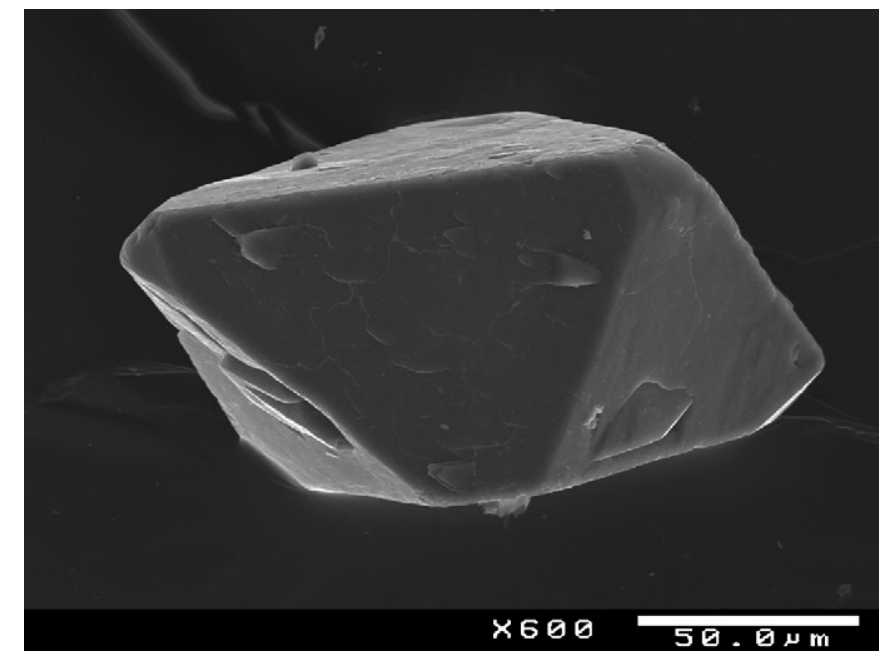

Fig. 3. SEM image illustrating the octahedral growth habit of $\mathrm{K}\left[(\mathrm{FeV})\left(\mathrm{PO}_{4}\right)_{2}(\mathrm{OH})\right.$ $\left.\left(\mathrm{H}_{2} \mathrm{O}\right)\right] \cdot \mathrm{H}_{2} \mathrm{O}$.

The Mössbauer spectrum (see Appendix A) of $\mathrm{K}\left[(\mathrm{FeV})\left(\mathrm{PO}_{4}\right)_{2}(\mathrm{OH})\right.$ $\left.\left(\mathrm{H}_{2} \mathrm{O}\right)\right] \cdot \mathrm{H}_{2} \mathrm{O}$ shows the presence of about $94.1 \% \mathrm{Fe}^{3+}$ in the title compound, suggesting that $\mathrm{V}^{3+}$ instead of $\mathrm{VO}^{2+}$ exists in the framework, which agrees well with the magnetic results.

\subsection{Crystal structure}

The structure of $\mathrm{K}\left[(\mathrm{FeV})\left(\mathrm{PO}_{4}\right)_{2}(\mathrm{OH})\left(\mathrm{H}_{2} \mathrm{O}\right)\right] \cdot \mathrm{H}_{2} \mathrm{O}$ comprises two crystallographically independent metallic centres $[M(1)$ and $M(2)]$ connected via a $\mu_{3}$-hydroxyl bridging group, two $\mu_{4}$-phosphate groups $\left(\mathrm{PO}_{4}^{3-}\right)$, two water molecules $[\mathrm{O}(1 \mathrm{~W})$ coordinated to $M(2)$, and $\mathrm{O}(2 \mathrm{~W})$ housed in the cavities present in the structure] plus a single $\mathrm{K}^{+}$charge-balancing counter-ion (Fig. 5). Information on crystallographic data collection and structure refinement details are summarized in Table 1.

The location of the $\mathrm{Fe}^{3+}$ and $\mathrm{V}^{3+}$ metallic centres is an interesting feature of $\mathrm{K}\left[(\mathrm{FeV})\left(\mathrm{PO}_{4}\right)_{2}(\mathrm{OH})\left(\mathrm{H}_{2} \mathrm{O}\right)\right] \cdot \mathrm{H}_{2} \mathrm{O}$. Although the present structure solution in $P 2_{1} / c$ indicates two different crystallographic sites (Fig. 5), from electron density maps it is clear that $\mathrm{Fe}^{3+}$ and $\mathrm{V}^{3+}$ are indeed statistically disordered (fixed rate of occupancy $50 \%$ ) over these two locations.

Two symmetry-related $\mu_{3}$-hydroxyl bridges lead to the formation of a centrosymmetric $\left[M_{4}\left(\mu_{3}-\mathrm{O}\right)_{2} \mathrm{O}_{18}\right]^{28-}$ tetra-nuclear metallic cluster (Figs. 1 and 6$)$ composed of two central edge-shared $\left\{M(1) \mathrm{O}_{6}\right\}$ plus two peripheral corner-shared $\left\{M(2) \mathrm{O}_{6}\right\}$ octahedra. This metal oxide core (butterfly cluster type) is surrounded by the $\mu_{4}$-bridging $\mathrm{PO}_{4}^{3-}$ groups, forming an anionic building unit: $\left[\mathrm{M}_{4}\left(\mu_{3}-\mathrm{OH}\right)_{2}\left(\mathrm{H}_{2} \mathrm{O}\right)_{2}\left(\mathrm{PO}_{4}\right)_{6}\right]^{8-}$, commonly found among minerals chemically analogous to leucophosphite and in a number of framework-type phosphates [23-26]. The four metallic centres composing this tetra-nuclear anionic cluster are located on the same plane, while the two $\mu_{3}-\mathrm{O}$ atoms lying ca. $0.57 \AA$ above and below that plane have a deviation angle of about $28.3^{\circ}$. The shortest metallic distance found in $\mathrm{K}\left[(\mathrm{FeV})\left(\mathrm{PO}_{4}\right)_{2}(\mathrm{OH})\left(\mathrm{H}_{2} \mathrm{O}\right)\right] \cdot \mathrm{H}_{2} \mathrm{O}$ is 3.073(1) $\AA$ for the central $M(1) \cdots M(1)^{i}$ arrangement [symmetry transformation: (i) $-x+1,-y+2,-z+2$ ]. Moreover, this physical separation between magnetic centres is considerably shorter than the remaining ones arising from the tetra-nuclear metallic arrangement: $M(1) \cdots M(2)$ of $3.767(1) \AA, \quad M(1) \cdots M(2)^{i}$ of 3.801(1) $\AA$ and $M(2) \cdots M(2)^{i}$ of $6.916(1) \AA$. The three-dimensional assembly of the $\left[\mathrm{M}_{4}\left(\mu_{3}-\mathrm{OH}\right)_{2}\left(\mathrm{H}_{2} \mathrm{O}\right)_{2}\left(\mathrm{PO}_{4}\right)_{6}\right]^{8-}$ building block leads to a framework-type material, with a system of intersecting channels (more notably observed along the [010] (Fig. 7) and [001] 


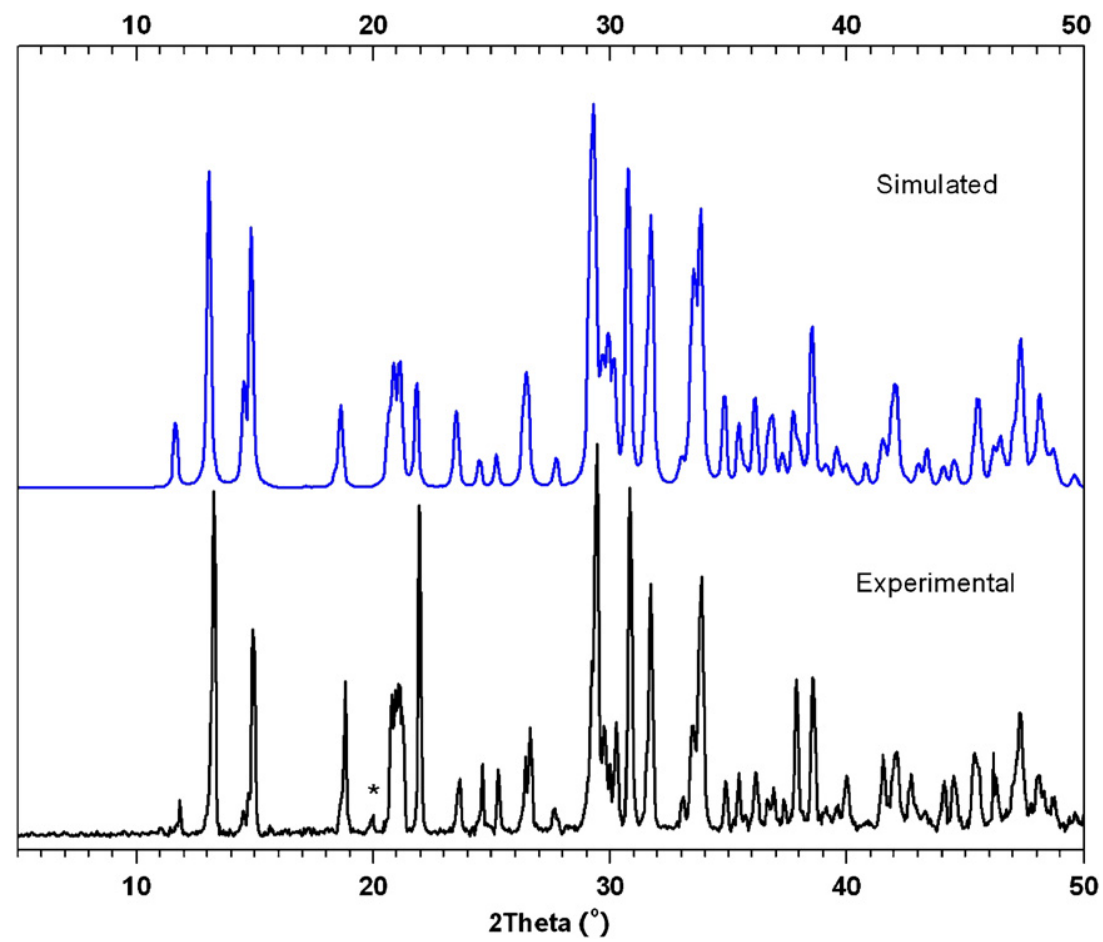

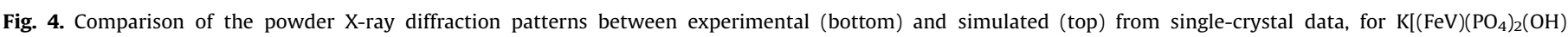
$\left.\left(\mathrm{H}_{2} \mathrm{O}\right)\right] \cdot \mathrm{H}_{2} \mathrm{O}$

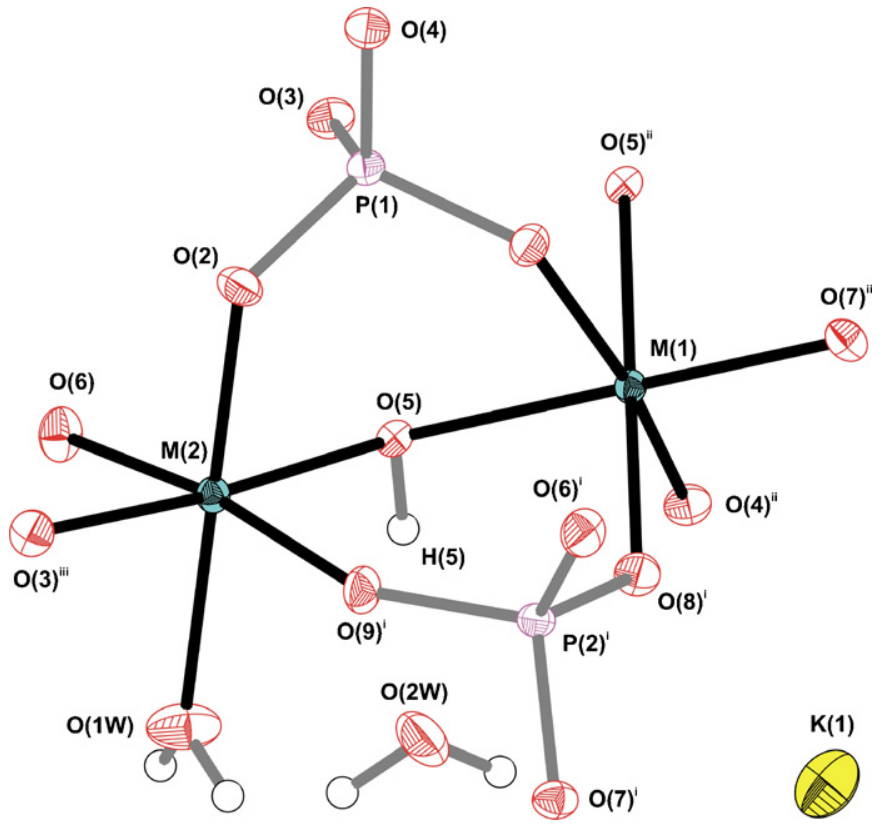

Fig. 5. Schematic representation of the octahedral $\left\{\mathrm{MO}_{6}\right\}$ coordination environments for the two crystallographically independent metallic centres, $M(1)$ and $M(2)$, showing the labelling scheme for all atoms. Thermal ellipsoids are drawn at the $30 \%$ probability level. For selected bond lengths and angles see Appendix A. Symmetry transformations used to generate equivalent atoms: (i) $x,-y+3 / 2, z-1 / 2$; (ii) $-x+1,-y+2,-z+2$; and (iii) $-x+2, y-1 / 2,-z+5 / 2$.

(see Appendix A) crystallographic directions) housing chargebalancing cations and water molecules of crystallization.

\subsection{Magnetism}

The magnetic susceptibility of the compound was measured from 300 to $4.5 \mathrm{~K}$ in a field of 100 Oe. The linearity at high
Table 1

Crystal and structure refinement data for $\mathrm{K}\left[(\mathrm{FeV})\left(\mathrm{PO}_{4}\right)_{2}(\mathrm{OH})\left(\mathrm{H}_{2} \mathrm{O}\right)\right] \cdot \mathrm{H}_{2} \mathrm{O}$

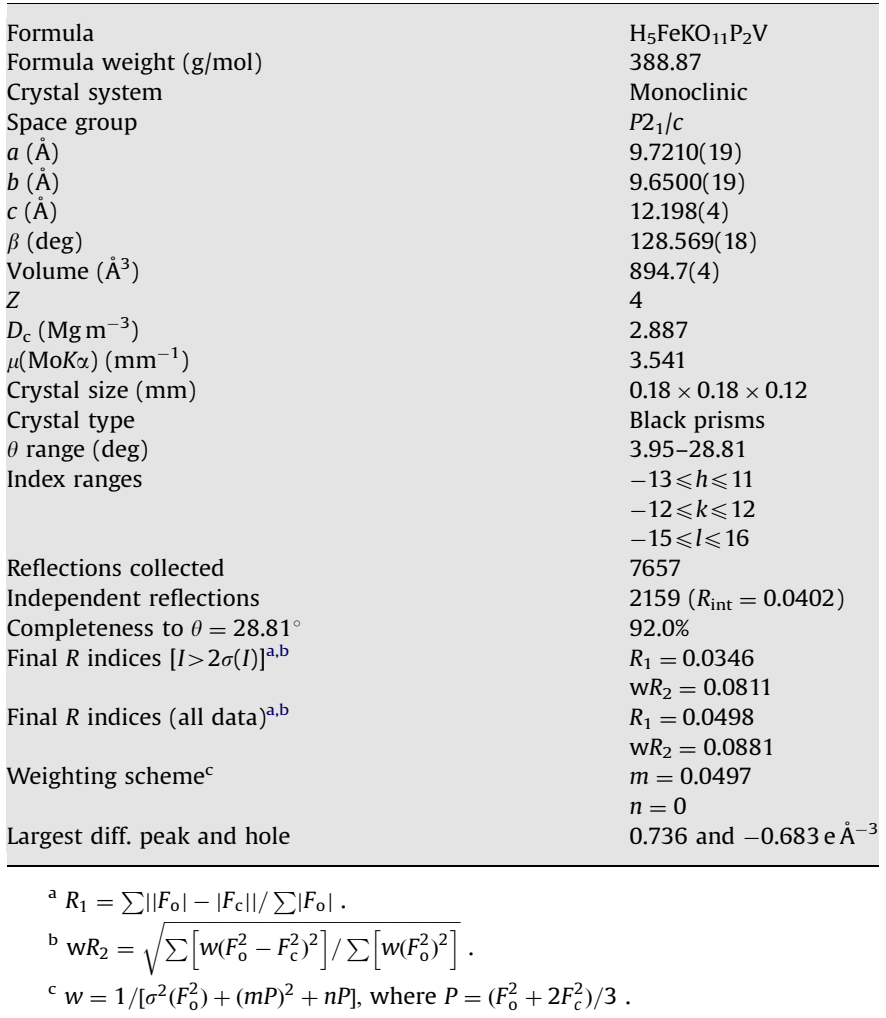

temperature of the inverse susceptibility plot indicates the absence of a significant $\chi_{0}$ term in the overall data. The strongly negative antiferromagnetic character of the magnetic interaction can be inferred by the extrapolation of a linear regression of the high-temperature data that intercepts the temperature axis at 


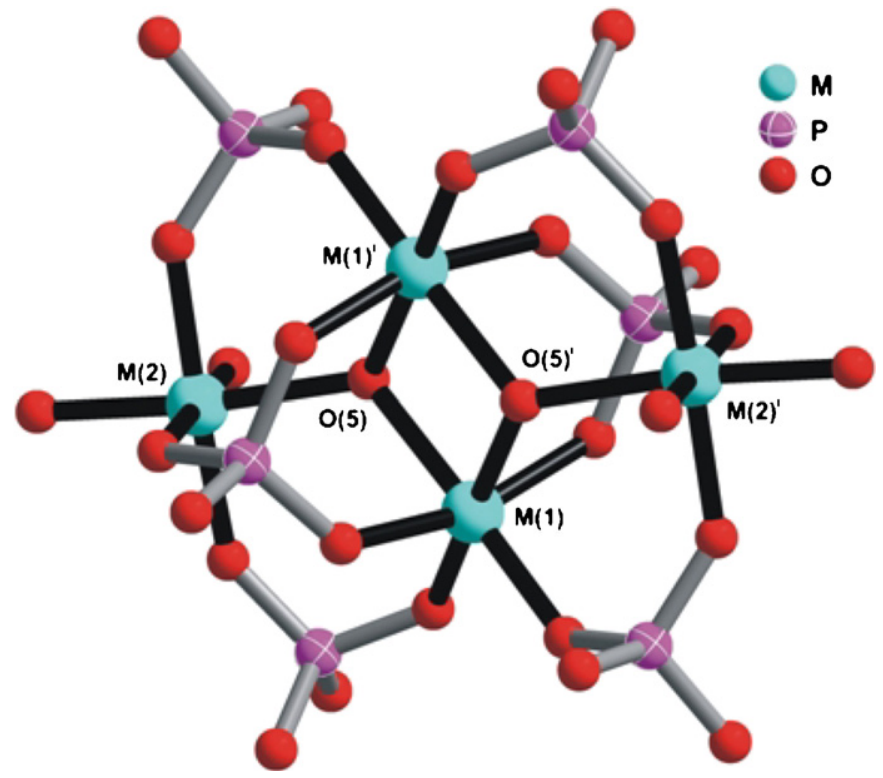

Fig. 6. Ball-and-stick representation of the "butterfly-shaped" anionic building block unit, $\left[M_{4}\left(\mu_{3}-\mathrm{OH}\right)_{2}\left(\mathrm{H}_{2} \mathrm{O}\right)_{2}\left(\mathrm{PO}_{4}\right)_{6}\right]^{8-}$. Hydrogen atoms omitted for clarity. Symmetry transformation used to generate equivalent atoms: (i) $-x+1,-y+2$, $-z+2$.

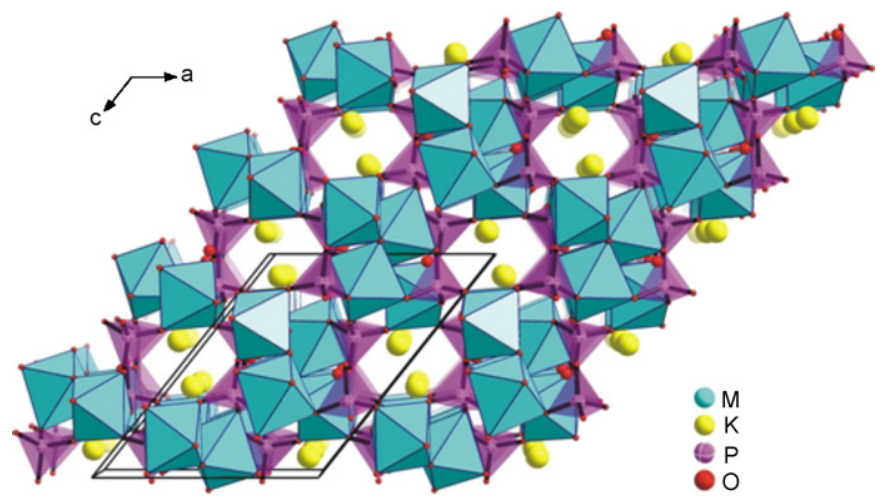

Fig. 7. Crystal packing of $\mathrm{K}\left[(\mathrm{FeV})\left(\mathrm{PO}_{4}\right)_{2}(\mathrm{OH})\left(\mathrm{H}_{2} \mathrm{O}\right)\right] \cdot \mathrm{H}_{2} \mathrm{O}$ viewed along the [010] direction of the unit cell. Hydrogen atoms omitted for clarity.

$\theta=-125 \mathrm{~K}$, a value in the range observed for other iron phosphates [10] (Figs. 8 and 9).

The effective spin for the sample calculated from a hightemperature Curie-Weiss law is $4.83 \mu_{\mathrm{B}}$. This value is in good agreement with the expected, $\mu_{\text {Expected }}=\sqrt{\left(\mu_{\mathrm{Fe}}^{2}+\mu_{\mathrm{V}}^{2}\right) / 2}=4.64 \mu_{\mathrm{B}}$ assuming two magnetic ions per mole of compound: one $\mathrm{Fe}^{3+}$ $(S=5 / 2)$ and one $\mathrm{V}^{3+}(S=1)$. The observed increase in the susceptibility at lower temperatures is not consistent with a simple antiferromagnetic order, and indicates that this compound shows ferrimagnetism, which is frequently observed in bimetallic compounds with different $S$. The simple mean field model which describes the ferrimagnetism of two interpenetrating lattices is described by Eq. (1). Here $C$ is the Curie constant and the temperatures $\theta_{\mathrm{P}}$ and $\theta$ are the asymptotes that limit the inverse susceptibility plot. Temperature $\theta$ is the low-temperature divergence of the system and can be interpreted as the ferrimagnetic ordering temperature of the system

$\frac{1}{\chi}=\frac{T+\theta_{\mathrm{P}}}{C}-\frac{\gamma}{T-\theta}$.
This model assumes two interpenetrating networks (A and B), with $W$ the molecular field coefficient between $\mathrm{A}$ and $\mathrm{B}$, while within each network the interactions are described by the coefficients $W_{\mathrm{AA}}=\alpha W$ and $W_{\mathrm{BB}}=\beta W$, usually both $\alpha$ and $\beta$ are less than 1. From Eq. (1), Eq. (2) [27] is obtained, which permits determination of the contribution of each network to the overall susceptibility of the system. The total Curie constant of the system, $C$, is the sum of the Curie constants of networks $A$ and $B, C=C_{A}+C_{B}$

$\chi=\frac{\left(C_{\mathrm{A}}+C_{\mathrm{B}}\right) T-C_{\mathrm{A}} C_{\mathrm{B}} W(2+\alpha+\beta)}{T^{2}-T W\left(C_{\mathrm{A}} \alpha+C_{\mathrm{B}} \beta\right)-C_{\mathrm{A}} C_{\mathrm{B}} W^{2}(1-\alpha \beta)}$.

In this compound there is inherent atomic disorder between $\mathrm{Fe}$ and $\mathrm{V}$, therefore each network does not correspond to a crystallographic sublattice, but to the set of Fe ions (with interaction $W_{\mathrm{Fe}}$ ) and $\mathrm{V}$ ions (with interaction $W_{\mathrm{V}}$ ) randomly distributed throughout the metal sites.

The results of fitting the data are shown in Table 2. To limit the number of free parameters both $C_{\mathrm{Fe}}$ and $C_{\mathrm{V}}$ were fixed for atomic proportions $1: 1$. The iron and vanadium sublattice interaction parameters are respectively $\alpha(\mathrm{Fe})=W / W_{\mathrm{Fe}}$ and $\beta(\mathrm{V})=W / W_{\mathrm{V}}$.

While a low value of $\theta$ is expected, since the structural complexity in all known iron phosphates is known to cause a large degree of magnetic frustration $\left(T_{\mathrm{N}} / \theta_{\mathrm{P}}<<1\right)$, and the inherent disorder enhances this effect, an unusual aspect of these fits is that $\theta<0$, which corresponds to a negative ferrimagnetic ordering temperature. From Eqs. (1) and (2) an analytical expression for $\theta$ can be obtained:

$\theta=W(2+\alpha+\beta) \frac{C_{\mathrm{A}} C_{\mathrm{B}}}{C_{\mathrm{A}}+C_{\mathrm{B}}}$.

From the inspection of this equation it can be seen that a negative asymptote $(\theta<0)$ can arise if one of the networks has a stronger antiferromagnetic interaction than the inter-network interaction, i.e. $0>W>W_{\mathrm{AA}}$ (or $W_{\mathrm{BB}}$ ), therefore $2+\alpha+\beta<0$. In fact, in the present situation not only $\left|W_{\mathrm{Fe}}\right|>2$, meaning that the $\mathrm{Fe}-\mathrm{Fe}$ interaction is stronger than $\mathrm{Fe}-\mathrm{V}$, but both $W_{\mathrm{Fe}}$ and $W_{\mathrm{V}}$ are antiferromagnetic. Although in most reported cases the intranetwork interaction is ferromagnetic, antiferromagnetic interaction between all the lattices can be observed in other ferrimagnets, for instance in some garnets and spinels [28]. It should be noted, however, that in those examples, the sign of the interaction is related to the site distribution in the structure (note that the Fe ion can have multiple oxidation states, and therefore different $S$ values), while in this compound the disorder definitely plays a role. The importance of the type of cation involved in the interaction is evidenced by the fact that $\left|W_{\mathrm{Fe}-\mathrm{Fe}}\right|>$ $\left|W_{\mathrm{Fe}-\mathrm{V}}\right|>\left|W_{\mathrm{V}-\mathrm{V}}\right|$, which is expected considering that the $\mathrm{Fe}^{3+}$ has half-filled $e_{g}$ orbitals ( $5 d$-electrons), which are more extended than the $\mathrm{V}^{3+} t_{2 g}$ orbitals and therefore increase the magnetic exchange across the iron sub-network.

\section{Conclusion}

In summary, the compound $\mathrm{K}\left[(\mathrm{FeV})\left(\mathrm{PO}_{4}\right)_{2}(\mathrm{OH})\left(\mathrm{H}_{2} \mathrm{O}\right)\right] \cdot \mathrm{H}_{2} \mathrm{O}$ was synthesized and its magnetic behaviour characterized. The susceptibility data are consistent with a frustrated ferrimagnet. The application of a localized magnetic moment mean field model converges on a negative ferrimagnetic Néel temperature. This anomaly is explained if all (inter- and intra-network) interactions are antiferromagnetic, and is in agreement with the crystal chemistry of the compound. This compound is the first example of an iron phosphate of type $\mathrm{K}\left[\mathrm{Fe}_{2}\left(\mathrm{PO}_{4}\right)_{2}(\mathrm{OH})\left(\mathrm{H}_{2} \mathrm{O}\right)\right] \cdot \mathrm{H}_{2} \mathrm{O}$ in which half the $\mathrm{Fe}^{3+}$ cations were replaced by $\mathrm{V}^{3+}$ cations. The design of such a compound provides a good model for investigating magnetic behaviour in hetero-nuclear metal clusters, thus 


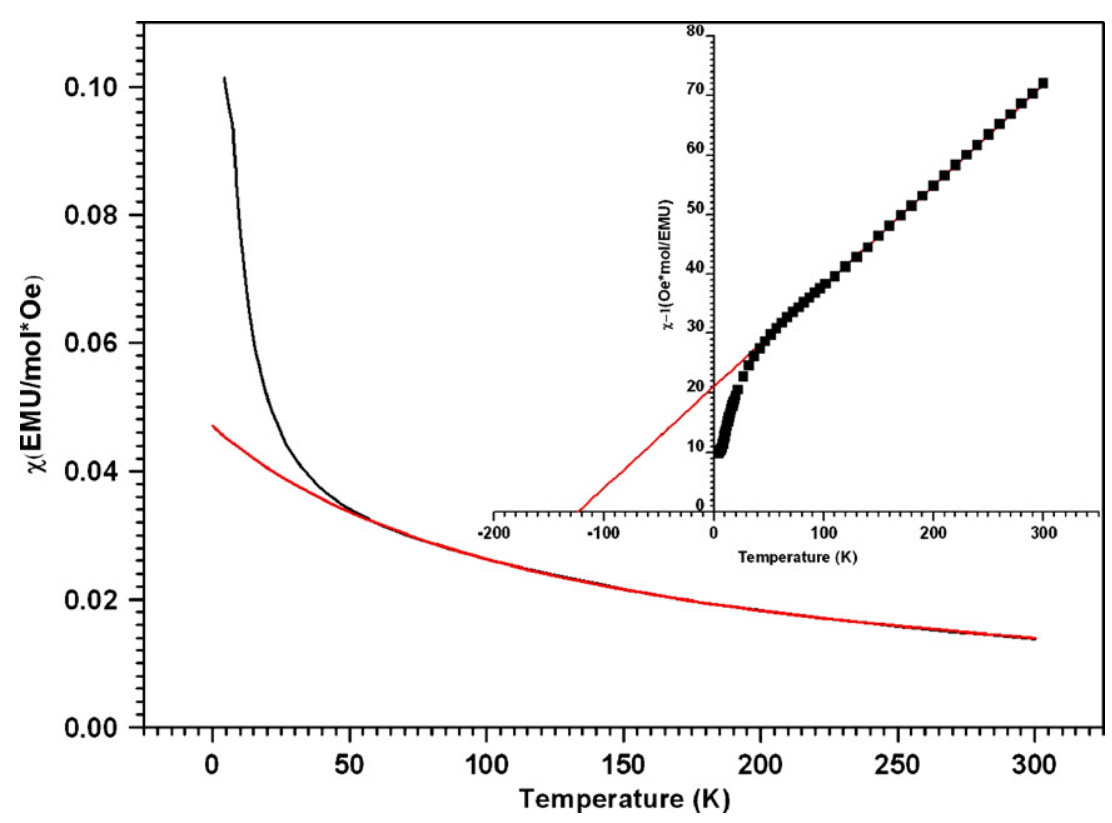

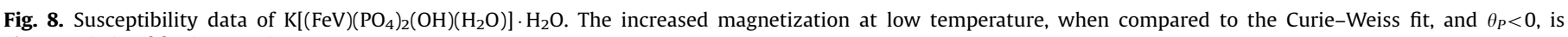
characteristic of ferrimagnetism.

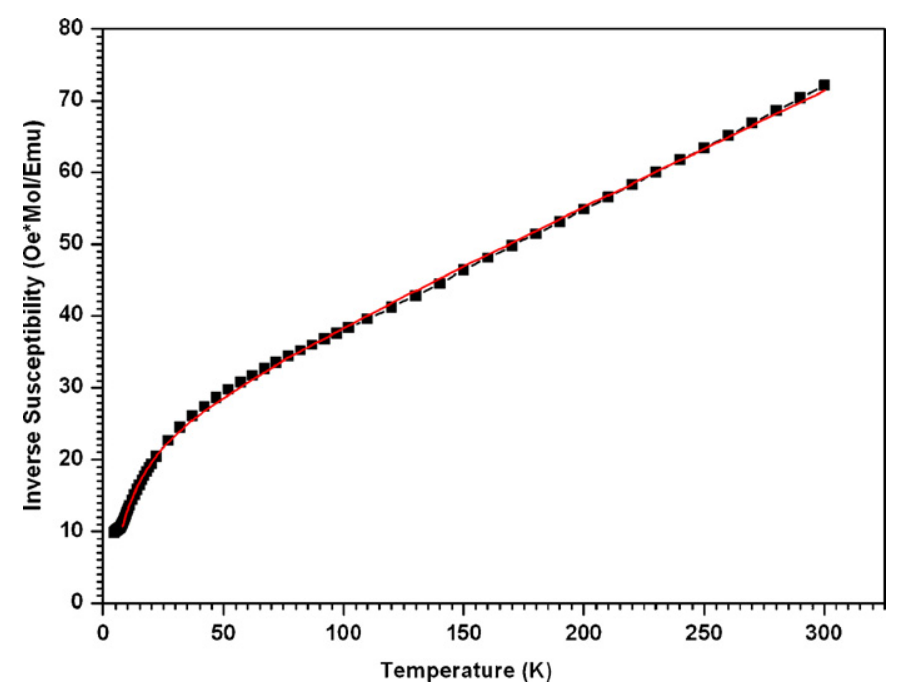

Fig. 9. Inverse susceptibility plot for compound $\mathrm{K}\left[(\mathrm{FeV})\left(\mathrm{PO}_{4}\right)_{2}(\mathrm{OH})\left(\mathrm{H}_{2} \mathrm{O}\right)\right] \cdot \mathrm{H}_{2} \mathrm{O}$. Dotted line experimental data, solid line the fit of the ferrimagnetic mean field model to the original data (see text).

Table 2

Results of the fit of the susceptibility data to Eqs. (1) and (2)

\begin{tabular}{lllllll}
\hline$C$ & $\theta_{P}$ & $\theta$ & $\gamma$ & $W$ & $\alpha_{\mathrm{Fe}}$ & $\beta_{\mathrm{V}}$ \\
\hline 7.17 & 205 & -14 & 419 & 14.3 & -2.55 & -0.38 \\
\hline
\end{tabular}

Note the change of parameter name $W_{\mathrm{Fe}}=\alpha$ and $W_{\mathrm{V}}=\beta$.

preparation of further materials with partial replacement of ferric ions by other transition metals is in progress.

\section{Acknowledgments}

We are grateful to FEDER, POCTI (Portugal), InTerreg IIIB and to the Portuguese Foundation for Science and Technology (FCT) for their general financial support and also for postdoctoral research Grant nos. SFRH/BPD/9309/2002 (to FNS), SFRH/BPD/14984/2004 (to AMS) and SFRH/BPD/14410/2003 (to LCS).

\section{Appendix A. Supplementary materials}

Supplementary data associated with this article can be found in the online version at doi:10.1016/j.jssc.2008.02.027.

\section{References}

[1] J.S. Miller, Adv. Mater. 6 (1994) 322.

[2] (a) X.M. Liu, S.Y. Fu, L.P. Zhu, J. Solid State Chem. 180 (2007) 461;

(b) S. Peng, S.H. Sun, Angew. Chem. Int. Ed. 46 (2007) 4155;

(c) X.M. Lin, A.C.S. Samia, J. Magn. Magn. Mater. 305 (2006) 100.

[3] (a) R. Jain, K. Kabir, J.B. Gilroy, K.A.R. Mitchell, K.C. Wong, R.G. Hicks, Nature 445 (2007) 291;

(b) Y. Numata, K. Inoue, N. Baranov, M. Kurmoo, K. Kikuchi, J. Am. Chem. Soc. 129 (2007) 9902;

(c) Z.H. Ni, L.F. Zhang, V. Tangoulis, W. Wernsdorfer, A.L. Cui, O. Sato, H.Z. Kou, Inorg. Chem. 46 (2007) 6029;

(d) C. Aronica, G. Chastanet, G. Pilet, B. Le Guennic, V. Robert, W. Wernsdorfer, D. Luneau, Inorg. Chem. 46 (2007) 6108;

(e) S. Tanase, J. Reedijk, Coordin. Chem. Rev. 250 (2006) 2501.

[4] J. Töpfer, J.B. Goodenough, J. Solid State Chem. 130 (1997) 117.

[5] (a) R. Basler, C. Boskovic, G. Chaboussant, H.U. Güdel, M. Murrie, S.T. Ochsenbein, A. Sieber, Chem. Phys. Chem 4 (2003) 910;

(b) D. Gatteschi, R. Sessoli, A. Cornia, Chem. Commun. 9 (2000) 725.

[6] (a) Y. Moreno, A. Vega, S. Ushak, R. Baggio, O. Peña, E. Le Fur, J.-Y. Pivan, E. Spodine, J. Mater. Chem. 13 (2003) 2381;

(b) E. Alda, B. Bazán, J.L. Mesa, J.L. Pizarro, M.I. Arriortua, T. Rojo, J. Solid State Chem. 173 (2003) 101.

[7] K.F. Hsu, S.L. Wang, Inorg. Chem. 39 (2000) 1773.

[8] C. du Peloux, P. Mialane, A. Dolbecq, J. Marrot, E. Rivière, F. Sécheresse, J. Mater. Chem. 11 (2001) 3392.

[9] (a) S. Benmokhtar, A. El Jazouli, J.P. Chaminade, P. Gravereau, A. Wattiaux, L. Fournès, J.C. Grenier, D. Waal, J. Solid State Chem. 179 (2006) 3709;

(b) M. Hidouri, B. Lajmi, A. Wattiaux, L. Fournés, J. Darriet, M.B. Amara, J. Solid State Chem. 179 (2006) 1808;

(c) M. Hidouri, B. Lajmi, A. Wattiaux, L. Fournés, J. Darriet, M.B. Amara, J. Solid State Chem. 177 (2004) 55.

[10] M. Riou-Cavellec, D. Riou, G. Férey, Inorg. Chim. Acta 291 (1999) 317.

[11] E.S. Simpson, J. Roy. Soc. West. Aust. 18 (1932) 69.

[12] P.B. Moore, Am. Mineral. 57 (1972) 397.

[13] S. Dick, T. Zeiske, J. Solid State Chem. 133 (1997) 508. 
[14] (a) P.J. Dunn, R.C. Rouse, T.J. Campbell, W.L. Roberts, Am. Mineral. 69 (1984) 374;

(b) M.J. Wilson, D.C. Bain, Mineral. Mag. 50 (1986) 291;

(c) M. Cavellec, D. Riou, G. Férey, Acta Crystallogr. C50 (1994) 1379.

[15] P. Chaudhuri, M. Winter, P. Fleischhauer, W. Haase, U. Flörke, H.-J. Haupt, Inorg. Chim. Acta 212 (1993) 241.

[16] R. Boca, Theoretical Foundations of Molecular Magnetism, Elsevier, Lausanne, 1999.

[17] (a) F.N. Shi, F.A.A. Paz, P.I. Girginova, H.I.S. Nogueira, J. Rocha, V.S. Amaral, J. Klinowski, T. Trindade, J. Solid State Chem. 179 (2006) 1497;

(b) F.A.A. Paz, F.N. Shi, T. Trindade, J. Rocha, J. Klinowski, Acta Crystallogr. E59 (2003) m179;

(c) F.N. Shi, J. Rocha, T. Trindade, Mater. Lett. 59 (2005) 652;

(d) F.N. Shi, F.A.A. Paz, J. Rocha, J. Klinowski, T. Trindade, Eur. J. Inorg. Chem. (2004) 3031;

(e) F.N. Shi, F.A.A. Paz, J. Rocha, J. Klinowski, T. Trindade, Inorg. Chim. Acta 358 (2005) 927.
[18] T. Kottke, D. Stalke, J. Appl. Crystallogr. 26 (1993) 615.

19] KUMA CRYSALIS CCD, Kuma Diffraction, Wroclaw, Poland, 1999.

[20] KUMA CRYSALIS RED, Kuma Diffraction, Wroclaw, Poland, 1999.

[21] G.M. Sheldrick, SHELXS-97, Program for Crystal Structure Solution, University of Göttingen, Göttingen, 1997.

[22] G.M. Sheldrick, SHELXL-97, Program for Crystal Structure Refinement, University of Göttingen, Göttingen, 1997.

[23] S. Krivovichev, Topology of Microporous Structures, 57, Mineralogical Society of America, 2005.

[24] G. Férey, Chem. Mater. 13 (2001) 3084.

[25] G. Férey, C. R. Acad. Sci. Ser. II C1 (1998) 1.

[26] G. Férey, J. Fluorine Chem. 72 (1995) 187.

27] B. Barbara, D. Gignoux, C. Vettier, Lectures on Modern Magnetism, Science Press, Springer, 1988.

[28] J.B. Goodenough, Magnetism and the Chemical Bond, Krieger Publishing Company, 1976 